\title{
Presentation of Results Using Poly-L-Lactic Acid in the Treatment of Orofacial Harmonization
}

\author{
Borghetti $N^{1}$, Pessoa de Barros $T^{2 *}$, Chaves $A^{3}$, Rodrigues $\mathrm{DA}^{4}$ and Teixeira $\mathrm{RG}^{5}$ \\ ${ }^{1}$ Dental Surgeon, Specialist in Orofacial Harmonization, Santa Catarina, Brazil \\ ${ }^{2}$ Dental Surgeon, Specialist in Orofacial Harmonization, Oral and Maxillofacial Surgery, Coordinator of the NAEO/AVANTIS Orofacial Harmonization \\ Program. Santa Catarina, FAPES/FACON Brazil Orofacial Harmonization Program, São Paulo, UNIESP Paraíba, Brazil \\ ${ }^{3}$ Dentist, Specialist in BucoMaxillofacial Surgery, Orofacial Harmonization, Sao Paulo, Brazil \\ ${ }^{4}$ Dentist, Specialist in Orofacial Harmonization, São Paulo, Brazil \\ ${ }^{5}$ Dentist, specialist in Oral and Maxilofacial Surgery, São Leopoldo Mandic School, São Paulo, Brazil
}

${ }^{\star}$ Corresponding author: Pessoa de Barros T, Dental surgeon, Specialist in Orofacial Harmonization, Oral and Maxillofacial Surgery, Coordinator of the NAEO/ AVANTIS Orofacial Harmonization Program. Santa Catarina, FAPES/FACON Brazil Orofacial Harmonization Program, São Paulo, UNIESP Paraíba, Brazil

Received: November 19, 2020; Accepted: November 26, 2020; Published: November 28, 2020

\begin{abstract}
This work aims to present a case report with the use of poly-L-lactic acid for facial rejuvenation, aiming to restore the loss of soft tissue volume resulting from the natural aging process. The patient underwent treatment in 2018. The product was reconstituted in $6 \mathrm{ml}$ of saline, left to stand for a period of 48 hours and at the time of application $2 \mathrm{ml}$ of $2 \%$ lidocaine without vasocontritor were added. The treatment was individualized according to the patient's specific volume and facial contour. The results were analyzed using pre- and post-procedure photographs and taking into account the perception of the harmonization context. The patient was satisfied with the result obtained. Despite the immense range of injectable products to increase facial volume, including hyaluronic acid, calcium hydroxyapatite and polymethylmethacrylate, poly-L-lactic acid proved to be a differentiated product presenting excellent results.
\end{abstract}

Keywords: Poly-L-lactic acid, Collagen, Facial rejuvenation

\section{Introduction}

Aging is a slow, progressive and inevitable process. Its occurrence involves a conjunction of intrinsic and extrinsic factors. Intrinsic aging, recognized as chronological, is physiological and natural, a result of decreased cellular metabolic activity and generally influenced by the genetic factor. But far beyond organic occurrences are factors extrinsic to aging, components that interfere and even intensify the natural events already described. Excessive exposure to ultraviolet rays and smoking can be considered the strongest determinants of the aging process. Such events involve the organism globally, but the structural loss of bone, muscle and skin is evident in regard to aesthetic repercussions, including the facial [1].

Structural loss of facial support tissues associated with physiological factors trigger a series of occurrences such as wrinkles (dynamic or static), displacement and ptosis of fat bags in addition to facial flaccidity, the latter resulting from a decrease in the production of collagen and elastin. Given the facts, the search for youthful appearance became necessary, bringing to reality the development of innovative techniques, invasive or not, in addition to the expansion of technology for the production of cosmetic products such as hyaluronic acid, calcium hydroxyapatite and polymethylmethacrylate.

Promising products include poly-L-lactic acid, approved by the Food and Drug Administration (FDA) in August 2004 and later in Europe, Canada, Australia and Brazil. Initially indicated for the treatment of lipodystrophy caused by HIV (in English, human immunodeficiency virus), the indication was extended to healthy patients who envisioned aesthetic resolution in cases of facial flaccidity [2]. This study aims to present the experience obtained in a clinical case, in which poly- L-lactic acid was used for cosmetic purposes, seeking to restore facial volume and improving its quality through the treatment of static wrinkles, mainly in the middle and lower thirds of the face.

\section{Literature Review}

Since the middle of 1898 , the inclusion of materials on the face has been accepted in order to improve aesthetics. With the advent of anesthesia and the improvement of surgical procedures, in the middle of the 19th century, aesthetic procedures became more invasive. Initially, most common procedures used fat as a graft to fill volumes after trauma. In the 20th century, autologous fat became the most common filler. However, removing fat and transporting it is an invasive and time-consuming procedure that in many cases has no lasting effect. The search for an effective material with a bio stimulating effect resulted in the discovery of poly-L-lactic acid [3].

In fact, the best indication for the product is using it as a biostimulator in patients who want a natural appearance associated with the improvement of the facial flaccidity. These effects are obtained 
with the injection of the product mainly in the facial contour regions, including mandibular lines, nasogenian grooves, temporal region, malar region in addition to the correction of marionette lines [4].

Poly-L-lactic acid is a stimulator of neocolagenesis, showing results that last for about 2 years, longer than it's tissue degradation (approximately 9 months), showing the stability of the collagen fibers produced. The technology involved in the production of the material is based on the fermentation of corn dextrose, which allows the synthesis of a heavy molecule ( $140 \mathrm{k}$ Dalton), crystalline, with $2 \mu \mathrm{m}$ to $50 \mu \mathrm{m}$ in diameter and that under non-enzymatic tissue hydrolysis degrades to lactic acid monomers. Such monomers are phagocytosed by macrophages, degraded to glucose and carbon dioxide that will be eliminated by the respiratory route. It has a biocompatible and biodegradable character, and, in addition, allergic testing is not necessary [3].

Its clinical effects are due to the stimulus of a desired controlled subclinical inflammatory response, which leads to the recruitment of monocytes, macrophages and fibroblasts. As poly-L-lactic acid is metabolized, collagen deposition is increased with a consequent increase in dermal thickness. The production of type I collagen begins about 10 days after application and continues for a period ranging from eight to 24 months. During it's period of activity, poly-L-lactic acid is gradually degraded by hydrolysis followed by oxidation of lactic acid. At the end of metabolization, substrate excretion occurs through urine, feces and respiration [5].

The product is packaged in a glass bottle containing a sterile lyophilized powder composed of microparticles of Poly-L-lactic Acid (PLLA), non-pyrogenic mannitol and sodium carboxymethylcellulose. It is recommended to be reconstituted with $6 \mathrm{ml}$ of serum (depending on the case it can be changed to $8 \mathrm{ml}$ ). The bottle should not be shaken immediately after reconstitution, to avoid depositing particles not yet hydrated on its wall. After reconstitution, the product should be left to stand for a period of 24 to 72 hours before application and preferably be storage at ambient temperature (up to $30^{\circ} \mathrm{C}$ ) or refrigerated (from $2^{\circ} \mathrm{C}$ to $8^{\circ} \mathrm{C}$ ) for up to 72 hours. The longer the resting time, the greater the hydration and, consequently, the easier it is to apply without obstructing the needle. After this period, $2 \mathrm{~mL}$ of lidocaine (without vasoconstrictor) must be added to the vial, immediately before application; the final volume will be $10 \mathrm{~mL}, 8 \mathrm{~mL}$ of polyL-lactic acid hydrated with distilled water and $2 \mathrm{~mL}$ of anesthetic. Immediately before it's use, the product should be gently stirred for better homogenization, but not vigorously, in order to avoid foaming inside the bottle [2].

The PLLA use should be avoided in some facial areas, such as perioral and periorbital regions, which are regions of muscle hypermobility, and are not indicated for lip filling. Adverse reactions related PLLA use appear mainly at the injection sites of the product, such as bruises, edema, papules, nodules and granulomas [4].

\section{Case Report}

Leucoderma patient, female, 58 years old, attended the dental clinic of the specialization course in Orofacial Harmonization with a complaint of saggy skin and numerous expression lines (Figure 1).
The product was reconstituted following the manufacturer's recommendations: $6 \mathrm{~mL}$ of $0.9 \%$ saline 48 hours before the procedure. Prior to the injections, $2 \mathrm{ml}$ of $2 \%$ lidocaine without vasoconstrictor were added. After the aseptic maneuvers of the skin and adequate anesthesia, the product was introduced into the deep dermis, close to the subcutaneous tissue, using $22 \mathrm{G}$ cannulas through retroinjection technique. We gave priority to the middle and lower third of the face, including regions of the malar, maxilla, nasogenian groove and mandibular contour. At the end, a massage of the treated area was carried out in order to distribute and unify the product.

After 15 days of application, it's possible to notice an improvement in the quality of the skin with a considerable decrease in static wrinkles in the middle third (Figure 2). The patient denies having felt or presented any type of adverse reaction to the procedure.

After 30 days, a significant improvement in the mandibular contour is observed, as well as the smoothing of the expression lines and attenuating facial sagging (Figures 3 and 4).

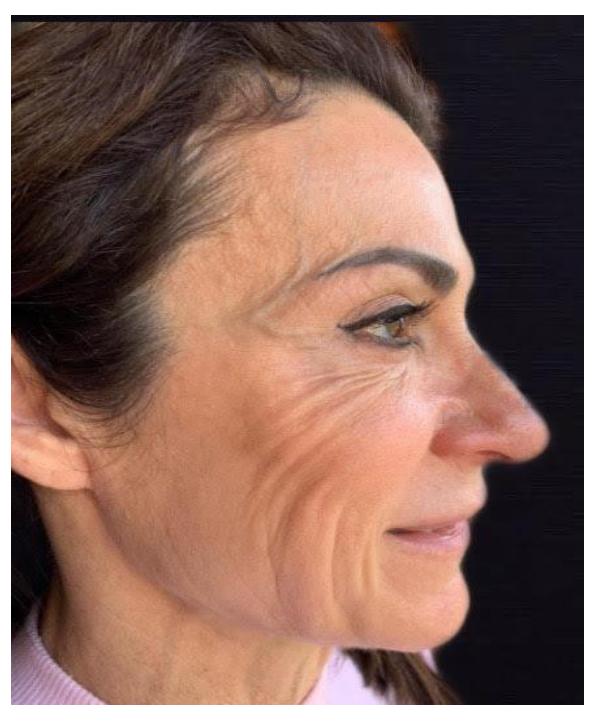

Figure 1: Start day.

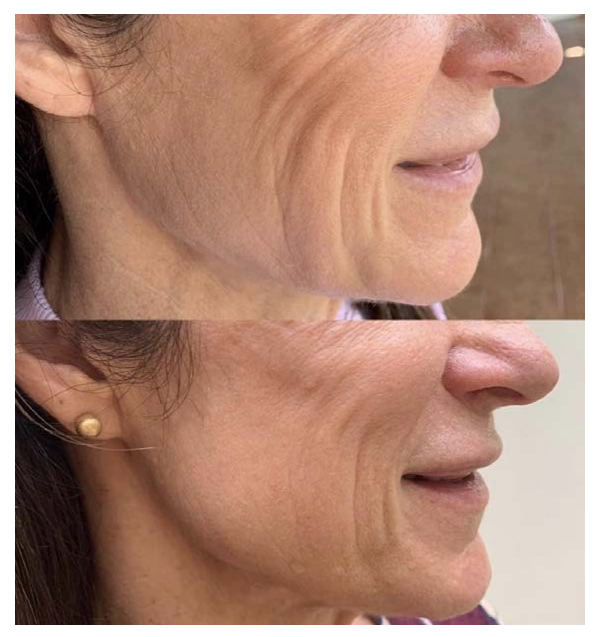

Figure 2: Initial day and 15 days. 


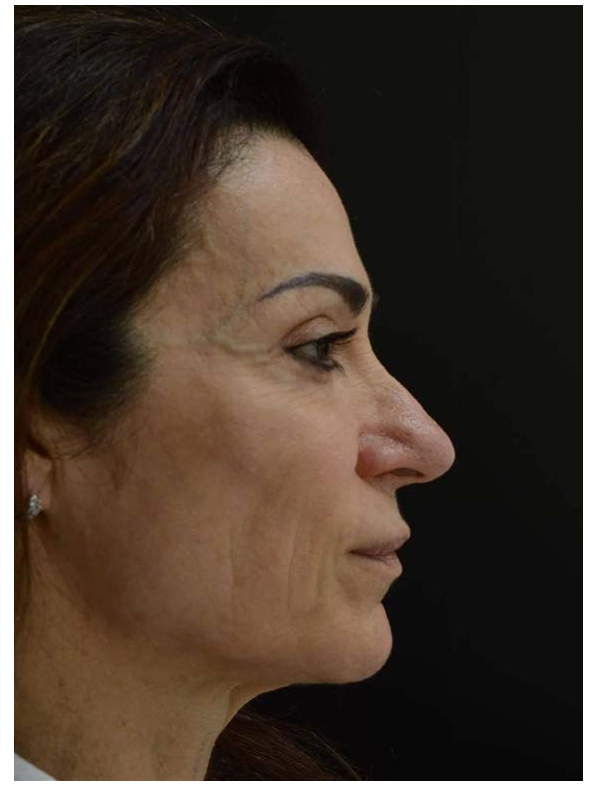

Figure 3: 30 days.

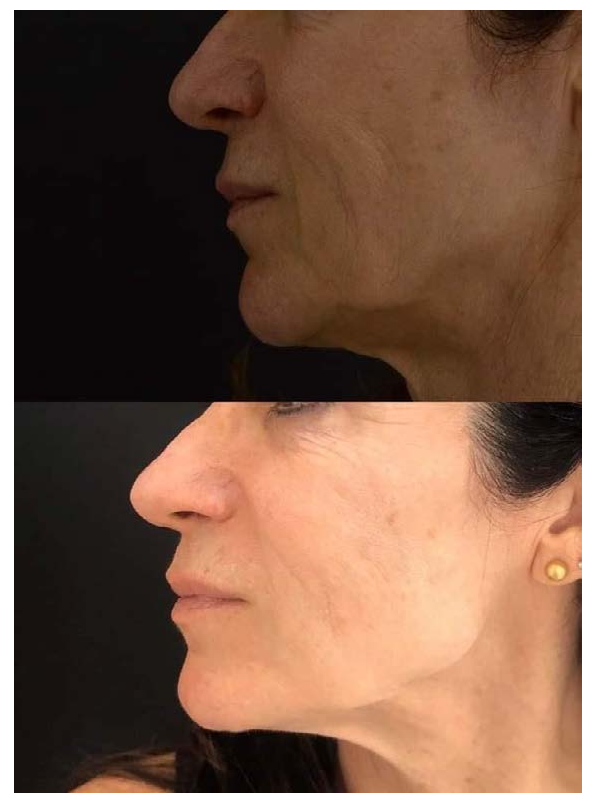

Figure 4: 30 days.

\section{Final Considerations}

The use of poly-L-lactic acid has been shown to be effective in the treatment of sagging skin, softening expression lines, improving mandibular contour and contributing to the restoration of facial harmony.

\section{References}

1. Sveikata K, Balciuniene I, Tutkuviene J (2011) Factors influencing face aging. Literature review. Stomatologija, Baltic Dental and Maxillofacial Journal 13: 113-115. [crossref]

2. Haddad A, Kadunc BV, Guarnieri C, Noviello JS, Gonzaga da Cunha M, et al. (2017) Conceitos atuais no uso do ácido poli-l-láctico para rejuvenescimento facial: Revisão e aspectos práticos. Surg Cosmet Dermatol 9: 60-71.

3. Silva RMSF, Cardoso GF (2013) Uso do ácido poli-L-láctico como restaurador de volume facial. Rev Bras Cir Plást 28: 223-226.

4. Machado Filho CDS, Santos TC, Rodrigues APLJM, Cunha MG (2013) Ácido PoliLLáctico: Um agente bioestimulador. Surg Cosmet Dermatol.

5. Antonio CR, Tridico LA (2019) Biomodulação celular: O futuro da Dermatologia. Surg Cosmet Dermatol.

\section{Citation:}

Borghetti N, Pessoa de Barros T, Chaves A, Rodrigues DA, Teixeira RG (2020) Presentation of Results Using Poly-L-Lactic Acid in the Treatment of Orofacial Harmonization.. Integr J Orthop Traumatol Volume 3(3): 1-3. 